\title{
Pure Squamous Cell Carcinoma of Gallbladder - A Rare Entity
}

Dr. Sayantan DE ${ }^{1}$, Dr. Madhumita Mondal ${ }^{2 *}$, Prof Mamata Guha Mallick Sinha ${ }^{3}$

${ }^{1}$ Post Graduate trainee, ${ }^{2}$ Assistant Professor, ${ }^{3}$ Professor Department of Pathology, IPGMER, West Bengal, India

DOI: $10.36347 /$ sjams.2021.v09i01.014

| Received: 19.12 .2020 | Accepted: 05.01.2021 | Published: 14.01.2021

*Corresponding author: Madhumita Mondal

\section{Abstract}

Case Report

Carcinoma of gallbladder is the most common malignancy of biliary tract and $5^{\text {th }}$ most common malignancy of gastrointestinal tract. Most common histological type being Adenocarcinoma. Though areas of squamous differentiation may be found in adenocarcinoma, pure squamous cell variant is very rare which accounts to less than $1 \%$ of all gallbladder carcinoma. To rule out adenosquamous variant the whole specimen must be meticulously studied. Gallbladder carcinoma is more common in women and usually seen in patients older than 50 years of age. Most are asymptomatic but at later stages It usually presents with pain abdomen mimicking features of cholecystitis. Although common mode of investigations is ultrasonography and CT scan, gallbladder cancer is commonly diagnosed incidentally after routine cholecystectomy. Gallbladder cancer carries a poor prognosis specially the squamous cell variant. In most cases at the time of diagnosis it already metastasizes to liver silently but 5 years survival rate can be improved if diagnosed before involving the liver. In our case a 50 years non-smoker multiparous woman presented with pain abdomen and vomiting for 7-8 months. USG and CT scan of abdomen revealed dilated lumen with mass in gallbladder along with calculi in both gallbladder and bile duct. She underwent radical cholecystectomy. On gross gallbladder showed multiple stones with eroded wall and ulcerative area in lumen measuring $3 \times 2 \times 5 \mathrm{~cm}$.Microscopic examination revealed gallbladder carcinoma of squamous cell variant without hepatic involvement after thorough examination. Squamous cell carcinoma because of its rarity and aggressiveness carries an outmost importance in its accurate diagnosis.

Keywords: Gallbladder Histological Cell Carcinoma.

Copyright $\left({ }_{0} 2021\right.$ The Author(s): This is an open-access article distributed under the terms of the Creative Commons Attribution 4.0 International License (CC BY-NC 4.0) which permits unrestricted use, distribution, and reproduction in any medium for non-commercial use provided the original author and source are credited.

\section{INTRODUCTION}

Carcinoma of gallbladder is a common malignancy of gastrointestinal tract. Adenocarcinoma (AC) is the most common histological variant. Although areas of squamous differentiation may be found in adenocarcinoma, pure primary squamous cell carcinoma is very rare. Squamous cell carcinoma of the gallbladder accounts for about less than $1 \%$ of all gallbladder cancer. Here we present a interesting case of pure squamous cell carcinoma of gallbladder in a 50 years old woman attaining the outdoor patient unit with recurrent pain in upper abdomen and vomitingmimicking features of chronic cholecystitis.

\section{CASe History}

A 50-year-old multiparous woman presented with a right upper quadrant abdominal pain along with vomiting for last 7-8 months. Biochemical parameters showed total protein: $8.1 \mathrm{~g} / \mathrm{dL}$, Alb: $4.65 \mathrm{~g} / \mathrm{dL}$, ALT: $140 \mathrm{IU}$, AST: $110 \mathrm{IU}$, Alkaline phosphatase: $796 \mathrm{IU}$, total bilirubin: $0.76 \mathrm{mg} / \mathrm{dL}$, and direct bilirubin: $0.23 \mathrm{mg} / \mathrm{dL}$.
Radiological examination revealed contracted gall bladder. Multiple calculi with mass $(4.17 \mathrm{~cm} \times 2.97 \mathrm{~cm})$ formation seen which is encasing the calculi. Biliary tree is marginally dilated. Multiple calculi seen in Common Bile Duct lumen (Figure 1).

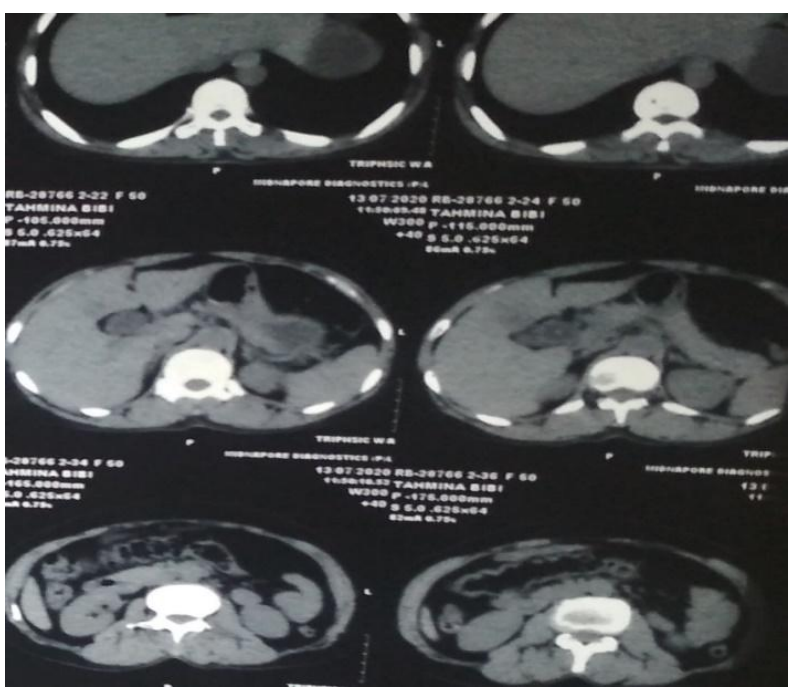

Fig-1 
Patient underwent radical cholecystectomy with retroduodenal, pericholedochal and caval lymph node dissection.

Grossly Gallbladder was adhered to the liver bed. On cut opening the gallbladder multiple stones were identified inside the lumen with erosion of the wall. The whole lumen was occupied by ulcerative area measuring $5 \times 3 \times 2 \mathrm{~cm}$ (Figure 2).

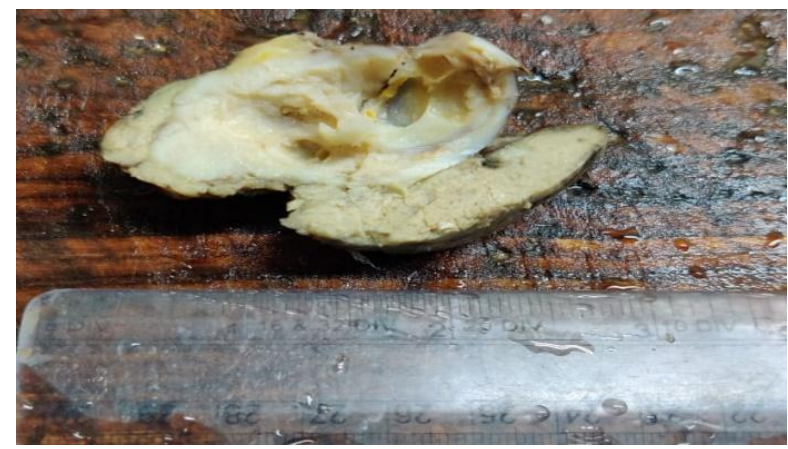

Fig-2

Histomorphological examination revealed infiltrating moderately differentiated squamous cell carcinoma of gallbladder invading the muscle layer upto liver bed with lymphovasular invasion. Thorough examination did not reveal any adenocarcinomatous component. All the lymph nodes (retroduodenal, pericholedochal and caval) were free from tumour invasion with TNM Stage- T2NOMx. (Figure 3 and Figure 4).

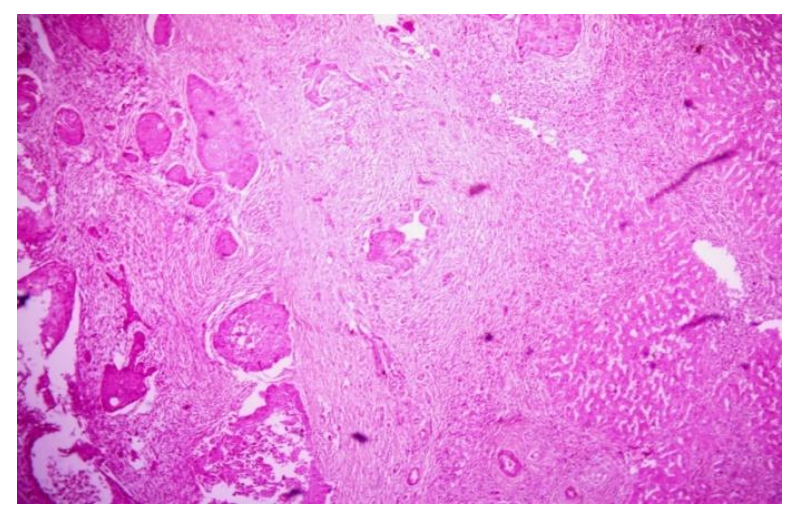

Fig-3: H\&E 40X

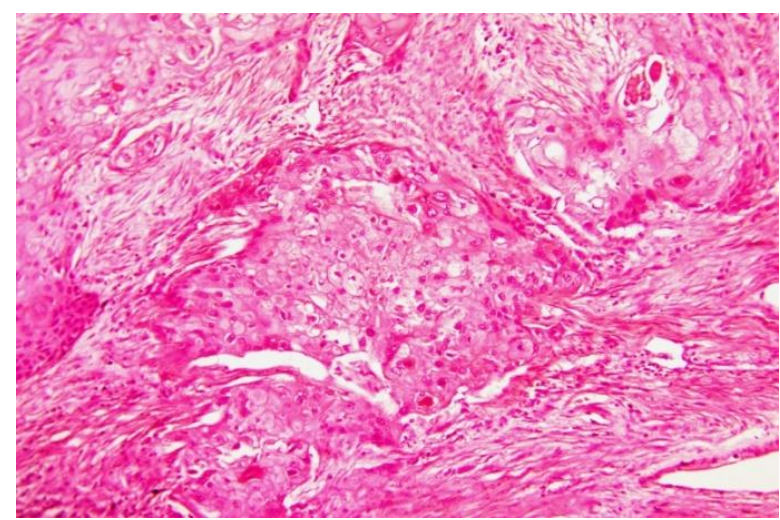

Fig-4: H\&E 100X

\section{DISCUSSION}

Gallbladder cancer is a rare neoplasm but most prevalent malignancy in the biliary tract [1]. Adenocarcinoma is the most common variant $(97 \%)$ but pure squamous cell carcinoma is rare subtype making up only $1 \%$ of all gallbladder carcinoma [2]. However, according to Khan et al. the incidence of pure squamous cell carcinoma varies from $0-3.5 \%$ [3].

The incidence of gallbladder cancer is higher in Asian countries like India, Japan [2]. Females are more prone to it (M: $n F-1: 3)$ [4]. It is predominantly seen between 4 th and 6 th decades of life. The most significant and common symptom is pain. However at times it may be clinically occult or may mimic cholecystitis [3]. In our case a 50 year old multiparous lady presented with right upper abdominal pain along with vomiting for last 7-8 months.

Regarding etiopathogenesis, chronic irritation of gallbladder from gallstones may trigger differentiation of gallbladder glandular cells into squamous cells. These squamous metaplastic cells would then undergo malignant transformation [2]. In our case the lumen of gallbladder was studded with stones.

More than $50 \%$ of cases presented with diffuse thickening of gallbladder wall radiologically, rest exhibit focal thickening or intraluminal mass [2]. In our case radiological examination revealed contracted gall bladder. Multiple calculi with mass $(4.17 \mathrm{~cm} \times 2.97 \mathrm{~cm})$ formation seen which is encasing the calculi.

Squamous cell carcinoma has the highest rates of proliferation and local invasiveness among gallbladder neoplasms [1].The mean survival time of the adenosquamous carcinoma/squamous cell carcinoma variant of gallbladder neoplasm reported about 23 months. In comparison, adenocarcinoma of the gallbladder it is 50 months [2]. Although some reports suggest that pure squamous cell carcinoma of the gallbladder grows slowly, is usually localized and rarely metastasized. On the other hand adenosquamous carcinoma is aggressive and metastasizes widely [5].

Radical resection of gallbladder without metastasis and local invasion can improve the outcome with adjuvant postoperative chemotherapy and radiotherapy, although there results are inconsistent and palliative only [3]. Our patient underwent radical cholecystectomy followed by chemotherapy and radiotherapy.

\section{Conclusion}

Early diagnosis of squamous cell carcinoma of gallbladder is very important for improving patient 
survival rate. Correct histological diagnosis is vital after examining the whole specimen.

\section{REFERENCE}

1. Aldossary MY, Alayed AA, Amr S, Alqahtani MS. Primary squamous cell carcinoma of the gallbladder: Report of a rare neoplasm from the Eastern Province of Saudi Arabia. Int J Surg Case Rep. 2018; 51:186-189.

2. Alpuerto AC, Mora ME, Robitsek RJ, Schubl SD. Primary Pure Squamous Cell Carcinoma of the Gallbladder Locally Invading the Liver,
Duodenum, and Stomach: A Case Report and Literature Review. Case Rep Surg. 2017; 2534029.

3. Khan N, Afroz N, Haider N, Khan MA. A case of pure endophytic squamous cell carcinoma of the gallbladder: a rare entity with aggressive behaviour. Turk Patoloji Derg. 2012;28(2):181-3.

4. Perisetti A, Raghavapuram S, Tharian B. Pure Squamous Cell Carcinoma of the Gallbladder Masquerading as a Hepatic Mass. Cureus. 2018;10(1):e2011.

5. Hosseinzadeh M, Shokripur M, Salahi H. Primary pure squamous cell carcinoma of gallbladder presenting as acute cholecystitis. Iran J Med Sci. 2012;37(4):271-273 